\title{
Prognostic value of KIT/PDGFRA mutations in gastrointestinal stromal tumors: a meta-analysis
}

\author{
Liang Zong ${ }^{1,2^{*}}$ and Ping Chen ${ }^{1}$
}

\begin{abstract}
Background: The postulated relationship between KIT/PDGFRA mutations and their prognostic value in gastrointestinal stromal tumors (GISTs) has generated intense attention during the past decade, despite the fact that a great deal of studies have been conducted on this subject. To provide a strong quantitative estimate of this postulated relationship, we carried out a meta-analysis which combined, compared, and summarized the results of existing relevant studies.

Methods: Studies were identified by searching databases and reviewing citations in relevant articles. Of 48 potentially relevant studies, we combined individual patient data from 18 studies which involved 1,487 patients with GISTs, by which we made a comparison between the positive KIT mutation subgroup and the negative KIT mutation subgroup (PDGFRA mutation and wild type). We tabulated and analyzed the patient characteristics from each study, including general information such as age and gender, histopathological parameters, and clinical follow-up outcomes.

Results: KIT mutations, compared with PDGFRA mutations and wild type, showed a marked increased risk not only for tumor size $(>5 \mathrm{~cm})$ but also for higher mitotic activity $(>5)$, suggesting that KIT mutations significantly correlated with the National Comprehensive Cancer Network (NCCN) high risk or National Institutes of Health (NIH) high risk (1.74 (95\% Cl, 1.20 to 2.53) and 2.00 (95\% Cl, 1.08 to 3.68), respectively). Moreover, higher recurrence and metastasis was observed in GISTs with KIT mutations, revealing its closer correlation with clinical malignant risk $(P<0.001$ for each, with odds ratio (OR) of 2.06 (95\%, 1.37 to 3.11$)$ and 2.77 (95\%, 1.64 to 4.67), respectively). High risk or malignant GISTs with KIT mutations had a significantly poorer prognosis, as measured by 3-year overall survival, compared to those with PDGFRA mutations and wild type (0.47 (95\% Cl, 0.25 to 0.90$)$ ).
\end{abstract}

Conclusions: KIT mutations, compared with PDGFRA mutations and wild type, represent a poorer prognostic marker in high risk or malignant GISTS.

Keywords: Gastrointestinal stromal tumors, KIT, PDGFRA, Prognosis, Meta-analysis

\section{Background}

Gastrointestinal stromal tumors (GISTs) are rare tumors, but are the most common primary mesenchymal tumor of the gastrointestinal tract [1]. GISTs express the tyrosine kinase receptor, KIT, which is the protein product of the KIT protooncogene. GISTs are generally characterized by gain-of-function mutations of KIT [2], and less often by PDGFRA or BRAF gene mutations [3-5]. In fact, the frequency of KIT/PDGFRA mutations in GISTs

\footnotetext{
*Correspondence: 250537471@qq.com

'Department of Gastrointestinal Surgery, Su Bei People's Hospital of Jiangsu Province, Yangzhou University, Yangzhou, Jiangsu Province 225001, China ${ }^{2}$ Department of Gastrointestinal Surgery, Graduate School of Medicine, University of Tokyo, 7-3-1 Hongo, Bunkyo-ku, Tokyo 113-8655, Japan
}

varies due to sample size, race, and geographic area. Around $85 \%$ of GISTs harbor mutations in KIT or PDGFRA [6].

To our knowledge, GISTs have a wide spectrum of biological behaviors ranging from benign to malignant. Due to the tumor's specific biological behavior, there is no standard definition of benignity and malignancy when a patient is diagnosed with GIST at an early stage. In 2001, the National Institutes of Health (NIH) recommended the use of risk assessment in predicting GIST behavior, in preference to trying to distinguish between benign and malignant lesions. They categorized GISTs into four groups on the basis of the combined parameters 
of tumor size and mitotic count, as follows: very low risk, low risk, intermediate risk, and high risk [7]. In 2006, another risk system for malignancy adding tumor site was established by the National Comprehensive Cancer Network (NCCN) criteria, based on Miettinen and Lasota's [8] Armed Forces Institute of Pathology (AFIP) stratification [9]. Although these systems are useful in predicting GIST behavior, it is based on the assumptions of a wide range of experts on GISTs.

KIT mutations were reported to associate with tumor metastasis and poor clinical outcome in GISTs [10]. On the contrary, PDGFRA mutations were typically characterized by clinically benign tumors [11,12]. Furthermore, the mutational status of KIT and PDGFRA is also a significant predictive factor for response to imatinib [13]. KIT and PDGFRA mutations appear to be related to outcome, but have not yet been integrated into the risk classification schemes. Previous studies were unable to distinguish the potential value of primary gene alterations in the risk of malignant biological behavior among gene subgroups or in controls to potentially confirm the variables examined [3,14-30]. This was possibly due to small sample sizes or confounding variables.

Therefore, we initiated an international collaborative effort which resulted in a meta-analysis of data on individual patients in prospective cohort studies to evaluate the prognostic value of KIT/PDGFRA mutations in GIST. To supply more powerful evidence, not only the tumor size, mitotic count, and tumor site, which have been used as parameters in NCCN criteria, but also clinical follow-up results such as recurrence, metastasis, and overall survival were tabulated and analyzed in our study.

\section{Methods}

\section{Publication search}

Two electronic databases (PubMed and Embase) were searched (last search was updated on 1 May 2012), using the search terms: 'gastrointestinal stromal tumor' and 'KIT/PDGFRA mutation'. All eligible studies were retrieved, and their bibliographies were checked for other relevant publications. Review articles and bibliographies of other relevant studies identified were hand-searched to identify additional eligible studies. Only published studies with full-text articles were included. When the same patient population was included in several publications, only the most recent or complete study was used in this meta-analysis (Figure 1).

\section{Inclusion criteria}

The inclusion criteria were as follows: 1) KIT/PDGFRA mutations and prognosis; 2) KIT/PDGFRA mutations in primary tumor before the treatment of imatinib; and 3) sufficient published data (more than 20 cases) to estimate an odds ratio (OR) with $95 \%$ confidence interval $(\mathrm{CI})$.

\section{Data extraction}

Information was carefully extracted from all eligible studies by two of the authors (LZ and PC), according to the inclusion criteria. The following data were collected from each study: study design (cohort, case-control, or cross-sectional), study population, sample size, total number of patients with positive KIT mutations and negative KIT mutations, and number of patients divided by age, gender, KIT expression, cell type, primary site, tumor size, mitotic count, recurrence, metastasis, and 3-year overall survival in those with and without KIT mutations, respectively.

\section{Statistical analysis}

The ORs with 95\% CI were used to assess the predictive value of KIT mutations on the malignant risk of GISTs, according to the method of Woolf. Heterogeneity assumption was confirmed by the $\chi^{2}$-based Q-test. A $P$ value greater than 0.10 for the $\mathrm{Q}$-test indicated a lack of heterogeneity among the studies, therefore the OR estimate for each study was calculated by the fixed effects model (the Mantel-Haenszel method). Otherwise, the random effects model (the DerSimonian and Laird method) was used. The significance of the pooled OR was determined by the Z-test and $P>0.05$ was considered statistically significant. Sensitivity analyses were carried out to determine if modification of the inclusion criteria for this meta-analysis affected the final results. An estimate of potential publication bias was carried out using the funnel plot, in which the OR for each study was plotted against its log (OR). An asymmetric plot suggested possible publication bias. Funnel plot asymmetry was assessed using Egger's linear regression test, a linear regression approach to measure funnel plot asymmetry on the natural logarithm scale of the OR. The significance of the intercept was determined by the $t$-test, as suggested by Egger $(P<0.05$ was considered representative of statistically significant publication bias). All statistical tests were performed with Review Manager, version 4.2 (The Cochrane Collaboration, Oxford, UK) and STATA, version 9.2 (Stata Corporation, College Station, TX, USA).

\section{Results}

\section{Study characteristics}

A total of 43 publications met the inclusion criteria [3,10,14-54]. A series of studies with single factor analysis of KIT gene mutations were excluded due to lack of controlled gene subgroups [10,31-36]. Studies by Wardelmann et al. and Koyama et al. were also excluded because they screened metastatic GIST patients specializing in 


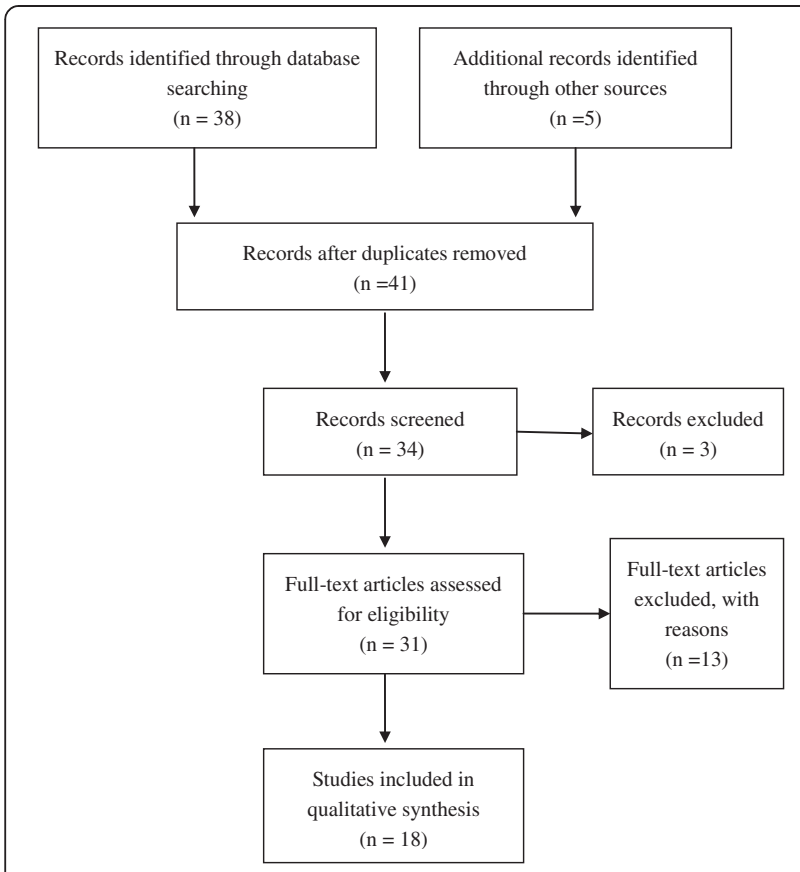

Figure 1 Flow chart of literature selection. secondary KIT mutations under treatment with imatinib $[37,38]$. In addition, the study by Kikuchi et al. was excluded because it focused on heterozygosity as a useful post-recurrence prognosis in screened patients with liver metastasis [39]. The studies by Zheng et al. were also excluded because the included articles contained the same patient population [40,41]. Other studies were excluded due to insufficient information to calculate OR [42-54]. Hence, a total of 18 studies including 1,487 patients were used in the pooled analyses. Table 1 lists the studies identified and their main characteristics. Of the 18 groups, the sample size ranged from 25 to 177 .

\section{General and pathological outcomes}

The meta-analysis of both age distribution and gender in the KIT mutation-positive versus -negative subgroups did not attain statistical significance $(1.08$ (95\% CI, 0.72 to $1.61 ; P=0.72)$ and $1.02(95 \% \mathrm{CI}, 0.77$ to $1.35 ; P=0.90)$, respectively) (Figure 2a,b). The overall OR for KIT expression in the KIT mutation-positive versus -negative subgroups was 2.79 (95\% CI, 1.49 to $5.21 ; P=0.001$ ) (Figure 2c). The overall OR for spindle cells in the KIT mutation-positive versus -negative subgroups revealed a significantly elevated risk in the KIT mutation-positive subgroup, but for the stomach as a primary site, this was seen in the KIT mutation-negative subgroup (3.19 (95\% CI, 1.71 to 5.93; $P=0.0003)$ and $0.56(95 \% \mathrm{CI}$,

Table 1 Main characteristics of all studies included in the meta-analysis

\begin{tabular}{|c|c|c|c|c|c|c|c|c|}
\hline Study & District & Study period & Study size & $\begin{array}{c}\text { Age } \\
\text { (mean, years) }\end{array}$ & $\begin{array}{c}\text { Gender } \\
\text { (male/female) }\end{array}$ & Subgroups & Prognostic system & $\begin{array}{l}\text { Follow-up time } \\
\text { (mean, years) }\end{array}$ \\
\hline Daniels [3] & Germany & 2011 & 87 & 64.9 & $45 / 42$ & KIT/PDGFRA/BRAF/WT & NCCN risk & NA \\
\hline Taniguchi [14] & Japan & 1999 & 124 & 60 & NA & KIT positive/negative & BM & 4.1 \\
\hline Sakurai [15] & Japan & 1999 & 48 & 59.4 & $21 / 27$ & KIT positive/negative & $\mathrm{BM}$ & 3.7 \\
\hline Yamamoto [16] & Japan & 2004 & 27 & 59 & $15 / 24$ & KIT/PDGFRA/WT & M-MIB index & 3.6 \\
\hline Lin [17] & Taiwan & 2006 & 25 & 63.2 & $13 / 12$ & KIT positive/negative & NA & NA \\
\hline Kim [18] & Korea & 2004 & 86 & 59.5 & $47 / 39$ & KIT positive/negative & $\mathrm{NIH}$ risk & NA \\
\hline Liu [19] & China & 2005 & 82 & 53 & $56 / 26$ & KIT positive/negative & BM & 4.1 \\
\hline Tzen [20] & Taiwan & 2007 & 134 & NA & $74 / 60$ & KIT/PDGFRA/WT & NA & 3.9 \\
\hline Cho [21] & Japan & 2006 & 56 & 61 & $35 / 21$ & KIT/PDGFRA/WT & BM & 4.7 \\
\hline Keun [22] & Korea & 2008 & 68 & 56 & $31 / 37$ & KIT/PDGFRA/WT & $\mathrm{NIH}$ risk & 5.0 \\
\hline Andersson [23] & Sweden & 2006 & 177 & NA & NA & KIT/PDGFRA/WT & MTR-KI67 index & 6.2 \\
\hline Haller [24] & Germany & 2005 & 38 & 64 & $22 / 16$ & KIT/PDGFRA/WT & $\mathrm{NIH}$ risk & 2.7 \\
\hline Steigen [25] & Norway & 2007 & 89 & 64.8 & $50 / 39$ & KIT/PDGFRA/WT & $\mathrm{BM}$ & NA \\
\hline Zheng [26] & China & 2011 & 25 & 58 & $15 / 10$ & KIT/PDGFRA/WT & MC-KI67 index & 3.2 \\
\hline Wardelmann [27] & Germany & 2003 & 55 & 62 & $29 / 26$ & KIT/PDGFRA/WT & $\mathrm{BM}$ & NA \\
\hline Martín [28] & Spain & 2005 & 162 & 63 & $82 / 80$ & KIT positive/negative & $\mathrm{NIH}$ risk & 3.5 \\
\hline Penzel [29] & Germany & 2005 & 79 & 60.9 & $41 / 38$ & KIT/PDGFRA/WT & $\mathrm{NIH}$ risk & NA \\
\hline Agaram [30] & America & 2006 & 125 & NA & NA & KIT/PDGFRA/WT & NA & NA \\
\hline
\end{tabular}

BM, benign to malignant; NA, not available; NCCN, National Comprehensive Cancer Network; NIH, National Institutes of Health; MC-KI67 index, mitotic count and Ki-67 index; M-MIB index, mitotic rate and MIB-1 index; MTR-KI67 index, maximum tumor size and Ki67 index; WT, wild type. 


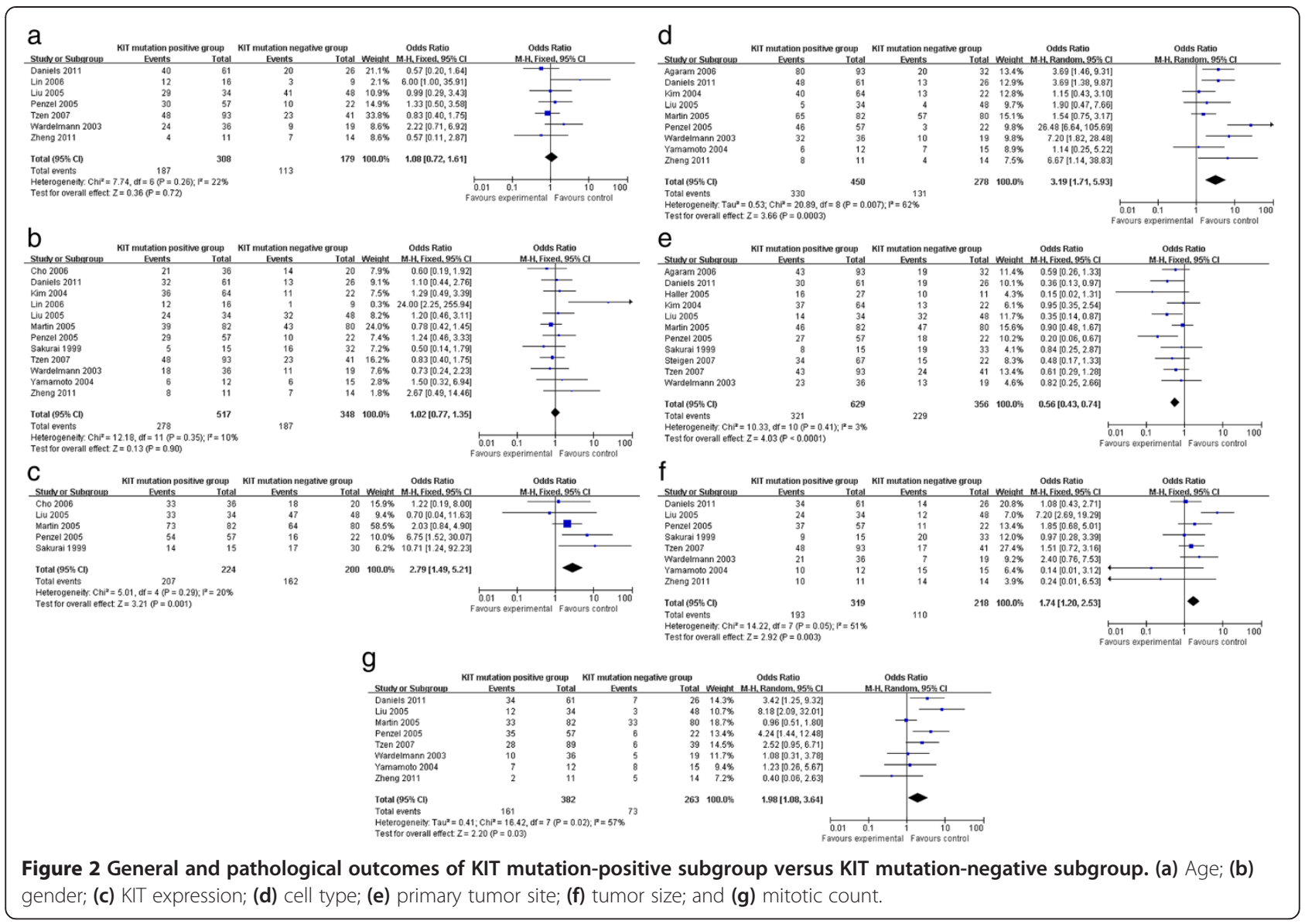

0.43 to $0.74 ; P<0.0001$ ), respectively) (Figure $2 \mathrm{~d}, \mathrm{e}$ ). However, an increased risk for larger tumor size $(>5 \mathrm{~cm})$ and higher mitotic activity $(>5)$ was observed in the KIT mutation-positive subgroup (1.74 (95\% CI, 1.20 to 2.53; $P=0.003)$ and 2.00 (95\% CI, 1.08 to $3.68 ; P=0.03)$, respectively) (Figure 2f,g).

\section{Clinical outcomes}

The KIT mutation-positive subgroup showed a significantly higher rate of recurrence and metastasis compared to the KIT mutation-negative subgroup (2.06 (95\% CI, 1.37 to $3.11 ; P=0.0005)$ and 2.77 (95\% CI, 1.64 to 4.67; $P=0.0001$ ), respectively) (Figure $3 \mathrm{a}, \mathrm{b})$. Moreover, KIT mutations demonstrated a worse prognosis in high risk or malignant GISTs, which was supported by the 3-year overall survival analysis (OR $0.47(95 \% \mathrm{CI}, 0.25$ to $0.90 ; P=0.02)$ ) (Figure 3c).

\section{Publication bias}

Begg's funnel plot was performed to assess publication bias. The heterogeneity tests for comparing the 18 combined studies showed heterogeneity in some analyses such as cell type and mitotic count; however, significant heterogeneity among the studies was not found (Table 2).
No single study influenced the pooled OR qualitatively as indicated by the sensitivity analyses (data not shown).

\section{Discussion and conclusion}

$\mathrm{NIH}$ and NCCN systems were established to predict GIST behavior using risk assessment (very low risk, low risk, intermediate risk, and high risk). However, it is still not clear whether internal molecular events correlate with malignant risk in GISTs. Molecular findings are critical in understanding the pathogenesis of GISTs. In 1998, Hirota et al. made the landmark discovery that the majority of GISTs harbor an activating mutation in the KIT oncogene [2]. Just 5 years later, Heinrich et al. identified oncogenic mutations in PDGFRA in a small subset of GISTs lacking KIT mutations, which meant that the mutations in PDGFRA and KIT were mutually exclusive [4]. Since then, subsequent evidence has shown that these mutations are pathogenetic for GIST initiation. However, between $10 \%$ and $15 \%$ of GISTs do not have KIT or PDGFRA mutations (known as wild type GISTs) and are a heterogeneous group, and in a recent study mutations in BRAF were found [3].

To date, many studies have focused on stratifying GISTs into prognostic categories based on mutational 


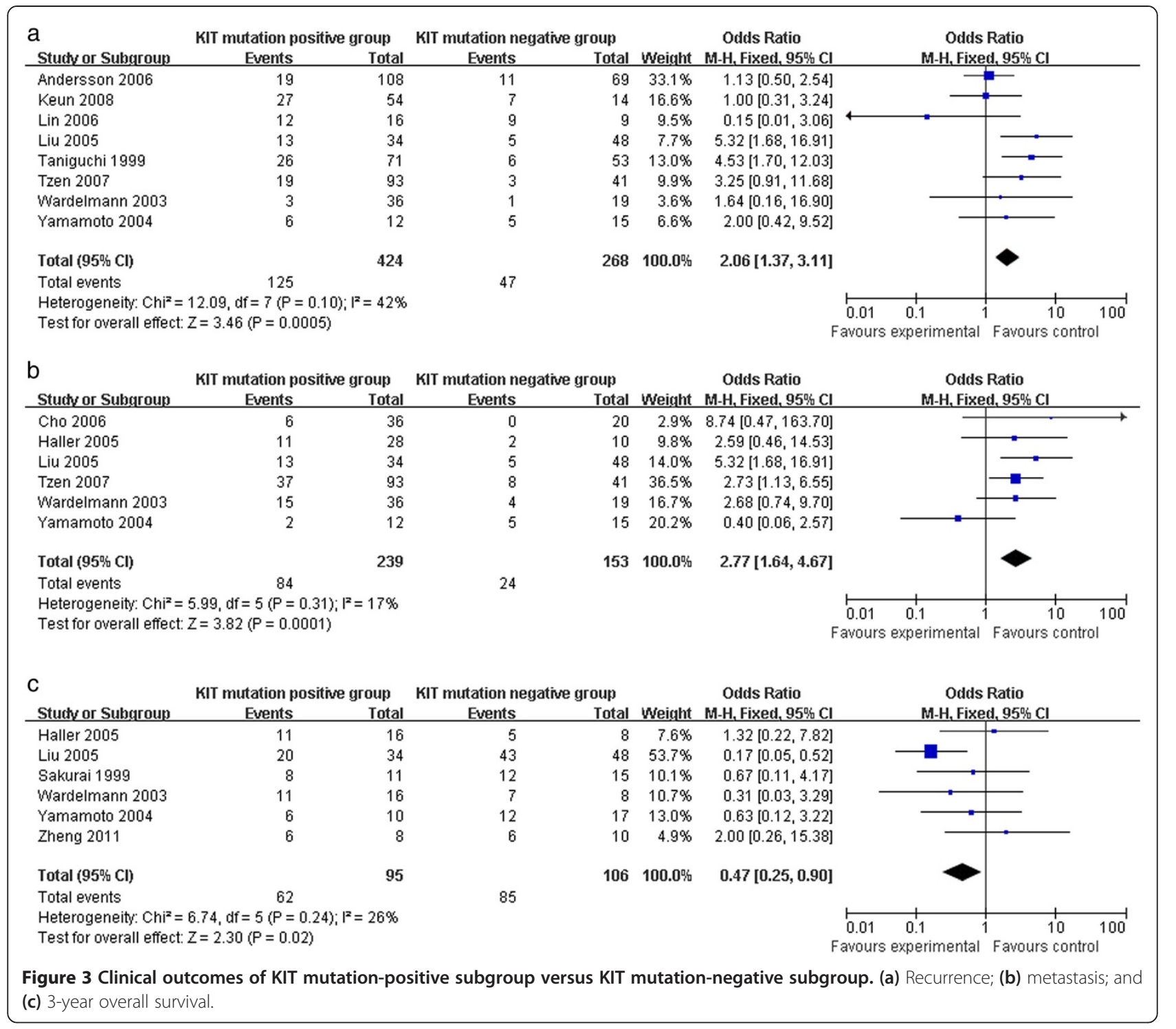

types, besides tumor size, mitotic count, and tumor site. But these studies showed controversial results and raised high concern. For example, Taniguchi et al. showed that KIT mutation was an independent prognostic factor for overall and cause-specific survival in patients with GISTs, whereas Sakurai et al. and Yamamoto et al. failed to observe such an association [14-16]. Lin et al. suggested that KIT mutation, compared with PDGFRA mutation and wild type, was often found in male patients and was more frequently found in those with large GISTs; however, they did not determine the predictive value of KIT and PDGFRA mutations [17]. In contrast, Kim et al. suggested that KIT mutation, along with high mitotic count and larger tumor size, had a strong prognostic value [18]. Prospective data have been criticized as being less convincing due to small sample size and the lack of statistical power to integrate sporadic individual studies. With a goal to explore the prognostic value of KIT/ PDGFRA mutations, we performed this meta-analysis to derive an overall pooled estimation of published studies. Since KIT mutations were proportionally more frequent than PDGFRA mutations and wild type, we divided all GISTs into KIT mutation-positive and -negative subtypes (PDGFRA mutations and wild type).

In analysis of mutation subtypes and biological behavior of GISTs, the results were as follows: 1) KIT mutations correlated with higher KIT expression level than PDGFRA mutations and wild type; 2) KIT mutations had a preference for spindle cell in histology; 3) PDGFRA mutations and wild type more frequently occurred in the stomach; and 4) KIT mutations showed a marked increased risk in both larger tumor size $(>5 \mathrm{~cm})$ and higher mitotic count $(>5)$, which revealed that KIT mutations significantly correlated with NCCN high risk or NIH high risk. 
Table 2 Outcomes of the meta-analysis

\begin{tabular}{|c|c|c|c|c|c|c|c|}
\hline \multirow{2}{*}{ Parameter } & \multirow{2}{*}{$\begin{array}{c}\text { Included } \\
\text { studies }\end{array}$} & \multicolumn{2}{|c|}{ Sample size } & \multirow{2}{*}{ Heterogeneity } & \multirow{2}{*}{ OR } & \multirow{2}{*}{$\begin{array}{c}95 \% \mathrm{Cl} \text { of } \\
\text { overall effect }\end{array}$} & \multirow{2}{*}{$P$ value } \\
\hline & & KIT mutation-positive & KIT mutation-negative & & & & \\
\hline Age ( $\geq 40$ years) & 7 & 308 & 179 & $P=0.26, I^{2}=22.4 \%$ & 1.08 & 0.72 to 1.61 & $P=0.72$ \\
\hline Gender (male) & 12 & 517 & 348 & $P=0.35, I^{2}=9.7 \%$ & 1.02 & 0.77 to 1.35 & $P=0.90$ \\
\hline KIT expression & 5 & 224 & 200 & $P=0.29, I^{2}=20.2 \%$ & 2.79 & 1.49 to 5.21 & $P=0.001$ \\
\hline Cell type (spindle cell) & 9 & 450 & 278 & $P=0.007, I^{2}=61.7 \%$ & 3.19 & 1.71 to 5.93 & $P=0.0003$ \\
\hline Primary tumor site (stomach) & 11 & 629 & 356 & $P=0.41, I^{2}=3.2 \%$ & 0.56 & 0.43 to 0.74 & $P<0.0001$ \\
\hline Tumor size $(>5 \mathrm{~cm})$ & 8 & 319 & 218 & $P=0.05, I^{2}=50.8 \%$ & 1.74 & 1.20 to 2.53 & $P=0.003$ \\
\hline Mitotic count (>5) & 8 & 382 & 263 & $P=0.02, I^{2}=57.8 \%$ & 2.00 & 1.08 to 3.68 & $P=0.03$ \\
\hline Recurrence & 8 & 424 & 268 & $P=0.10, I^{2}=42.1 \%$ & 2.06 & 1.37 to 3.11 & $P=0.0005$ \\
\hline Metastasis & 6 & 239 & 153 & $P=0.31, I^{2}=16.5 \%$ & 2.77 & 1.64 to 4.67 & $P=0.0001$ \\
\hline 3-year overall survival & 6 & 95 & 106 & $P=0.24, I^{2}=25.8 \%$ & 0.47 & 0.25 to 0.90 & $P=0.02$ \\
\hline
\end{tabular}

Given these histopathological findings, we also examined the relationship between mutation subtypes and clinical follow-up outcomes, which revealed that KIT mutations correlated with higher malignant risks than PDGFRA mutations and wild type, mainly because of: 1) more frequent recurrences; 2) higher metastasis; and 3) a worse survival rate.

It is very interesting that KIT mutations in high risk or malignant GISTs represent a worse factor of prognosis than PDGFRA mutations and wild type based on our findings, but patients with KIT mutations benefit a lot from the targeted therapy of imatinib. On reviewing the latest studies, our previous results supported that patients with KIT mutations have improved response to imatinib treatment when compared with those with wild type. However, the longterm efficacy is not significant [13]. Moreover, patients with KIT mutations who initially benefit from imatinib treatment eventually develop drug resistance. Recent studies reported that those patients with secondary imatinib resistance are through polyclonal acquisition of second-site mutations in the kinase domain. Regardless of this, it has been proved that constitutive KIT/PDGFR activation promotes proliferation and inhibits apoptosis of neoplastic cells through the CCRP signaling pathway [55]. An alteration in CCRP is often implicated in the pathogenesis and tumor progression of various types of tumors. Therefore, secondary mutation and CCRB signaling pathway might be the possible mechanism to explain the discrepancy of KIT mutations in prognosis and target therapy.

\section{Abbreviations}

AFIP: Armed Forces Institute of Pathology; Cl: Confidence interval; GIST: Gastrointestinal stromal tumor; NCCN: National Comprehensive Cancer Network; NIH: National Institutes of Health; OR: Odds ratio.

\section{Competing interests}

The authors declare that there is no conflict of interest with regard to the following: employment, consultancies, stock ownership, honoraria, paid expert testimony, patent applications/registrations, and grants or other funding.

\section{Authors' contributions}

LZ and PC contributed equally to this manuscript. Both authors read and approved the final manuscript.

\section{Acknowledgements}

The authors declare that they have no potential conflict of interest.

Received: 14 November 2013 Accepted: 14 March 2014

Published: 28 March 2014

\section{References}

1. George S, Desai J: Management of gastrointestinal stromal tumors in the era of tyrosine kinase inhibitors. Curr Treat Options Oncol 2002, 3(6):489-496.

2. Hirota S, Isozaki K, Moriyama Y, Hashimoto K, Nishida T, Ishiguro S, Kawano K, Hanada M, Kurata A, Takeda M, Muhammad Tunio G, Matsuzawa Y, Kanakura Y, Shinomura Y, Kitamura Y: Gain-of-function mutations of c-kit in human gastrointestinal stromal tumors. Science 1998, 279(5350):577-580.

3. Daniels M, Lurkin I, Pauli R, Erbstösser E, Hildebrandt U, Hellwig K, Zschille U, Lüders P, Krüger G, Knolle J, Stengel B, Prall F, Hertel K, Lobeck H, Popp B, Theissig F, Wünsch P, Zwarthoff E, Agaimy A, Schneider-Stock R: Spectrum of KIT/PDGFRA/BRAF mutations and Phosphatidylinositol-3-Kinase pathway gene alterations in gastrointestinal stromal tumors (GIST). Cancer Lett 2011, 312(1):43-54.

4. Heinrich $M C$, Corless $C L$, Duensing A, McGreevey L, Chen CJ, Joseph N, Singer S, Griffith DJ, Haley A, Town A, Demetri GD, Fletcher CD, Fletcher JA: PDGFRA activating mutations in gastrointestinal stromal tumors. Science 2003, 299(5607):708-710.

5. Hirota S, Ohashi A, Nishida T, Isozaki K, Kinoshita K, Shinomura Y, Kitamura Y: Gain-of-function mutations of platelet-derived growth factor receptor alpha gene in gastrointestinal stromal tumors. Gastroenterology 2003, 125(3):660-667.

6. Miettinen M, Lasota J: Gastrointestinal stromal tumors: pathology and prognosis at different sites. Semin Diagn Pathol 2006, 23(2):70-83.

7. Fletcher CD, Berman JJ, Corless C, Gorstein F, Lasota J, Longley BJ, Miettinen M, O'Leary TJ, Remotti H, Rubin BP, Shmookler B, Sobin LH, Weiss SW: Diagnosis of gastrointestinal stromal tumors: a consensus approach. Hum Pathol 2002, 33(5):459-465.

8. Miettinen M, Lasota J: Gastrointestinal stromal tumors: review on morphology, molecular pathology, prognosis, and differential diagnosis. Arch Pathol Lab Med 2006, 130(10):1466-1478.

9. National Comprehensive Cancer Network (NCCN): NCCN Clinical Practice Guidelines in Oncology: Soft Tissue Sarcoma V.2.2009. Fort Washington, PA: NCCN; 2009

10. Lasota J, Vel Dobosz AJ, Wasag B, Wozniak A, Kraszewska E, Michej W, Ptaszynski K, Rutkowski P, Sarlomo-Rikala M, Steigen SE, Schneider-Stock R, Stachura J, Chosia M, Ogun G, Ruka W, Siedlecki JA, Miettinen M: Presence of homozygous KIT exon 11 mutations is strongly associated with 
malignant clinical behavior in gastrointestinal stromal tumors. Lab Invest 2007, 87(10):1029-1041.

11. Lasota J, Dansonka-Mieszkowska A, Sobin LH, Miettinen M: A great majority of GISTs with PDGFRA mutations represent gastric tumors of low or no malignant potential. Lab Invest 2004, 84(7):874-883.

12. Corless CL, Schroeder A, Griffith D, Town A, McGreevey L, Harrell P, Shiraga S, Bainbridge T, Morich J, Heinrich MC: PDGFRA mutations in gastrointestinal stromal tumors: frequency, spectrum and in vitro sensitivity to imatinib. J Clin Oncol 2005, 23(23):5357-5364.

13. Chen $\mathrm{P}$, Zong L, Zhao W, Shi L: Efficacy evaluation of imatinib treatment in patients with gastrointestinal stromal tumors: a meta-analysis. World J Gastroenterol 2010, 16(33):4227-4232.

14. Taniguchi M, Nishida T, Hirota S, Isozaki K, Ito T, Nomura T, Matsuda H, Kitamura Y: Effect of c-kit mutation on prognosis of gastrointestinal stromal tumors. Cancer Res 1999, 59(17):4297-4300.

15. Sakurai S, Fukasawa T, Chong JM, Tanaka A, Fukayama M: C-kit gene abnormalities in gastrointestinal stromal tumors (tumors of interstitial cells of Cajal). Jpn J Cancer Res 1999, 90(12):1321-1328.

16. Yamamoto H, Oda Y, Kawaguchi K, Nakamura N, Takahira T, Tamiya S, Saito T, Oshiro Y, Ohta M, Yao T, Tsuneyoshi M: c-kit and PDGFRA mutations in extragastrointestinal stromal tumor (gastrointestinal stromal tumor of the soft tissue). Am J Surg Pathol 2004, 28(4):479-488.

17. Lin SC, Liu CL, Wang TI, Chang WS, Tzen CY, Huang MJ: Clinical implications of C-kit gene mutation in patients with large gastrointestinal stromal tumors. J Gastroenterol Hepatol 2006, 21(10):1604-1608.

18. Kim TW, Lee H, Kang YK, Choe MS, Ryu MH, Chang HM, Kim JS, Yook JH, Kim BS, Lee JS: Prognostic significance of c-kit mutation in localized gastrointestinal stromal tumors. Clin Cancer Res 2004, 10(9):3076-3081.

19. Liu XH, Bai CG, Xie Q, Feng F, Xu ZY, Ma DL: Prognostic value of KIT mutation in gastrointestinal stromal tumors. World J Gastroenterol 2005, 11(25):3948-3952.

20. Tzen CY, Wang MN, Mau BL: Spectrum and prognostication of KIT and PDGFRA mutation in gastrointestinal stromal tumors. Eur J Surg Oncol 2008, 34(5):563-568.

21. Cho S, Kitadai Y, Yoshida S, Tanaka S, Yoshihara M, Yoshida K, Chayama K: Deletion of the KIT gene is associated with liver metastasis and poor prognosis in patients with gastrointestinal stromal tumor in the stomach. Int J Oncol 2006, 28(6):1361-1367.

22. Keun Park C, Lee EJ, Kim M, Lim HY, Choi DI, Noh JH, Sohn TS, Kim S, Kim MJ, Lee HK, Kim KM: Prognostic stratification of high-risk gastrointestinal stromal tumors in the era of targeted therapy. Ann Surg 2008, 247(6):1011-1018.

23. Andersson J, Bümming $P$, Meis-Kindblom JM, Sihto $H$, Nupponen $N$, Joensuu H, Odén A, Gustavsson B, Kindblom LG, Nilsson B: Gastrointestinal stromal tumors with KIT exon 11 deletions are associated with poor prognosis. Gastroenterology 2006, 130(6):1573-1581.

24. Haller F, Gunawan B, von Heydebreck A, Schwager S, Schulten HJ, Wolf-Salgó J, Langer C, Ramadori G, Sültmann H, Füzesi L: Prognostic role of E2F1 and members of the CDKN2A network in gastrointestinal stromal tumors. Clin Cancer Res 2005, 11(18):6589-6597.

25. Steigen SE, Eide TJ, Wasag B, Lasota J, Miettinen M: Mutations in gastrointestinal stromal tumors: a population-based study from Northern Norway. APMIS 2007, 115(4):289-298.

26. Zheng S, Huang KE, Tao DY, Pan YL: Gene mutations and prognostic factors analysis in extragastrointestinal stromal tumor of a Chinese three-center study. J Gastrointest Surg 2011, 15(4):675-681.

27. Wardelmann E, Losen I, Hans V, Neidt I, Speidel N, Bierhoff E, Heinicke T, Pietsch T, Büttner R, Merkelbach-Bruse S: Deletion of Trp-557 and Lys-558 in the juxtamembrane domain of the c-kit protooncogene is associated with metastatic behavior of gastrointestinal stromal tumors. Int J Cancer 2003, 106(6):887-895.

28. Martín J, Poveda A, Llombart-Bosch A, Ramos R, López-Guerrero JA, García Del Muro J, Maurel J, Calabuig S, Gutierrez A, de Sande JLG, Martínez J, De Juan A Laínez N, Losa F, Alija V, Escudero P, Casado A, García P, Blanco R, Buesa JM Spanish Group for Sarcoma Research: Deletions affecting codons 557-558 of the c-KIT gene indicate a poor prognosis in patients with completely resected gastrointestinal stromal tumors: a study by the Spanish Group for Sarcoma Research (GEIS). J Clin Oncol 2005, 23(25):6190-6198.

29. Penzel R, Aulmann S, Moock M, Schwarzbach M, Rieker RJ, Mechtersheimer G: The location of KIT and PDGFRA gene mutations in gastrointestinal stromal tumours is site and phenotype associated. J Clin Pathol 2005, 58(6):634-639.
30. Agaram NP, Baren A, Arkun K, Dematteo RP, Besmer P, Antonescu CR: Comparative ultrastructural analysis and KIT/PDGFRA genotype in 125 gastrointestinal stromal tumors. Ultrastruct Pathol 2006, 30(6):443-452.

31. Lasota J, Jasinski M, Sarlomo-Rikala M, Miettinen M: Mutations in exon 11 of c-Kit occur preferentially in malignant versus benign gastrointestinal stromal tumors and do not occur in leiomyomas or leiomyosarcomas. Am J Pathol 1999, 154(1):53-60.

32. Lasota J, Kopczynski J, Sarlomo-Rikala M, Schneider-Stock R, Stachura T, Kordek R, Michal M, Boltze C, Roessner A, Stachura J, Miettinen M: KIT 1530ins6 mutation defines a subset of predominantly malignant gastrointestinal stromal tumors of intestinal origin. Hum Pathol 2003, 34(12):1306-1312.

33. Miettinen $M$, Makhlouf $H$, Sobin LH, Lasota J: Gastrointestinal stromal tumors of the jejunum and ileum: a clinicopathologic, immunohistochemical, and molecular genetic study of 906 cases before imatinib with long-term follow-up. Am J Surg Pathol 2006, 30(4):477-489.

34. Antonescu CR, Sommer G, Sarran L, Tschernyavsky SJ, Riedel E, Woodruff JM, Robson M, Maki R, Brennan MF, Ladanyi M, DeMatteo RP, Besmer P: Association of KIT exon 9 mutations with nongastric primary site and aggressive behavior: KIT mutation analysis and clinical correlates of 120 gastrointestinal stromal tumors. Clin Cancer Res 2003, 9(9):3329-3337.

35. Yamaguchi M, Miyaki M, lijima T, Matsumoto T, Kuzume M, Matsumiya A Endo Y, Sanada Y, Kumada K: Specific mutation in exon 11 of c-kit protooncogene in a malignant gastrointestinal stromal tumor of the rectum. J Gastroenterol 2000, 35(10):779-783.

36. Gong L, Li YH, Zhao HD, Zhao JY, Zhang W: The clinicopathologic observation, c-KIT gene mutation and clonal status of gastrointestinal stromal tumor in the sacrum. BMC Gastroenterol 2009, 9:43.

37. Wardelmann E, Merkelbach-Bruse S, Pauls K, Thomas N, Schildhaus HU, Heinicke $T$, Speidel N, Pietsch T, Buettner R, Pink D, Reichardt $P$, Hohenberger $P$ : Polyclonal evolution of multiple secondary KIT mutations in gastrointestinal stromal tumors under treatment with imatinib mesylate. Clin Cancer Res 2006, 12(6):1743-1749.

38. Koyama T, Nimura H, Kobayashi K, Marushima H, Odaira H, Kashimura H, Mitsumori N, Yanaga K: Recurrent gastrointestinal stromal tumor (GIST) of the stomach associated with a novel c-kit mutation after imatinib treatment. Gastric Cancer 2006, 9(3):235-239.

39. Kikuchi H, Yamamoto M, Hiramatsu Y, Baba M, Ohta M, Kamiya K, Tanaka T, Suzuki S, Sugimura H, Kitagawa M, Kanai T, Kitayama Y, Kanda T, Nishikura K, Konno $\mathrm{H}$ : Effect of loss of heterozygosity of the c-kit gene on prognosis after hepatectomy for metastatic liver gastrointestinal stromal tumors. Cancer Sci 2007, 98(11):1734-1739.

40. Zheng S, Chen LR, Wang HJ, Chen SZ: Analysis of mutation and expression of c-kit and PDGFR-alpha gene in gastrointestinal stromal tumor. Hepatogastroenterology 2007, 54(80):2285-2290.

41. Zheng S, Pan YL, Tao DY, Wang JL, Huang KE: Secondary C-kit mutation is a cause of acquired resistance to imatinib in gastrointestinal stromal tumor. Scand J Gastroenterol 2009, 44(6):760-763.

42. Isaac JC, Willmore C, Holden JA, Layfield LJ: A c-kit-negative gastrointestinal stromal tumor with a platelet-derived growth factor receptor alpha mutation. Appl Immunohistochem Mol Morphol 2006, 14(1):52-56.

43. Fukasawa T, Chong JM, Sakurai S, Koshiishi N, Ikeno R, Tanaka A, Matsumoto Y, Hayashi Y, Koike M, Fukayama M: Allelic loss of $14 q$ and $22 q, N F 2$ mutation, and genetic instability occur independently of c-kit mutation in gastrointestinal stromal tumor. Jpn J Cancer Res 2000, 91(12):1241-1249.

44. Shibusawa Y, Tamura A, Mochiki E, Kamisaka K, Kimura H, Ishikawa O: c-kit Mutation in generalized lentigines associated with gastrointestinal stromal tumor. Dermatology 2004, 208(3):217-220.

45. Chen LL, Holden JA, Choi H, Zhu J, Wu EF, Jones KA, Ward JH, Andtbacka RH, Randall RL, Scaife CL, Hunt KK, Prieto VG, Raymond AK, Zhang W, Trent JC, Benjamin RS, Frazier ML: Evolution from heterozygous to homozygous KIT mutation in gastrointestinal stromal tumor correlates with the mechanism of mitotic nondisjunction and significant tumor progression. Mod Pathol 2008, 21(7):826-836.

46. Kuroda N, Tanida N, Hirota S, Daum O, Hes O, Michal M, Lee GH: Familial gastrointestinal stromal tumor with germ line mutation of the juxtamembrane domain of the KIT gene observed in relatively young women. Ann Diagn Pathol 2011, 15(5):358-361.

47. Maeyama H, Hidaka E, Ota H, Minami S, Kajiyama M, Kuraishi A, Mori H, Matsuda Y, Wada S, Sodeyama H, Nakata S, Kawamura N, Hata S, Watanabe M, lijima $Y$, Katsuyama T: Familial gastrointestinal stromal tumor with 
hyperpigmentation: association with a germline mutation of the c-kit gene. Gastroenterology 2001, 120(1):210-215

48. Namgung $\mathrm{H}$ : Gastrointestinal stromal tumor with KIT mutation in neurofibromatosis type 1.J Korean Surg Soc 2011, 81(4):276-280.

49. Lippai N, Füle T, Németh T, Benedek G, Mályi I, Pádi E, Sápi Z: Keratinpositive gastrointestinal stromal tumor of the stomach mimicking gastric carcinoma: diagnosis confirmed by c-kit mutation analysis. Diagn Mol Pathol 2008, 17(4):241-244.

50. Yasuoka R, Sakakura C, Shimomura K, Fujita Y, Nakanishi M, Aragane H, Hagiwara A, Bamba M, Abe T, Yamagishi H: Mutations in exon 11 of the c-kit gene in a myogenic tumor and a neurogenic tumor as well as in gastrointestinal stromal tumors. Utility of c-kit mutation as a prognostic biomarker for gastrointestinal mesenchymal tumor. Dig Surg 2003, 20(3):183-191.

51. Chou CC, Chou MJ, Tzen CY: Prediction of KIT mutation in gastrointestinal stromal tumors by the immunoprofile of the tumor cells. $J$ Formos Med Assoc 2010, 109(1):25-31.

52. Miselli FC, Casieri P, Negri T, Orsenigo M, Lagonigro MS, Gronchi A, Fiore M, Casali PG, Bertulli R, Carbone A, Pierotti MA, Tamborini E, Pilotti S: c-Kit/ PDGFRA gene status alterations possibly related to primary imatinib resistance in gastrointestinal stromal tumors. Clin Cancer Res 2007, 13(8):2369-2377.

53. Hostein I, Debiec-Rychter M, Olschwang S, Bringuier PP, Toffolati L, Gonzalez D, Forget S, Escande F, Morzuch L, Tamborini E, Faur N, Pilotti S, Dei Tos P, Emile JF, Coindre JM: A quality control program for mutation detection in KIT and PDGFRA in gastrointestinal stromal tumours. J Gastroenterol 2011, 46(5):586-594.

54. Haller F, Cortis J, Helfrich J, Cameron S, Schüler P, Schwager S, Gunawan B, Füzesi L, Agaimy A: Epithelioid/mixed phenotype in gastrointestinal stromal tumors with KIT mutation from the stomach is associated with accelerated passage of late phases of the cell cycle and shorter disease-free survival. Mod Pathol 2011, 24(2):248-255.

55. Zong L, Chen P, Xu Y: Correlation between P53 expression and malignant risk of gastrointestinal stromal tumors: evidence from 9 studies. Eur J Surg Oncol 2012, 38(3):189-195.

doi:10.1186/1477-7819-12-71

Cite this article as: Zong and Chen: Prognostic value of KIT/PDGFRA mutations in gastrointestinal stromal tumors: a meta-analysis. World Journal of Surgical Oncology 2014 12:71.

\section{Submit your next manuscript to BioMed Central and take full advantage of:}

- Convenient online submission

- Thorough peer review

- No space constraints or color figure charges

- Immediate publication on acceptance

- Inclusion in PubMed, CAS, Scopus and Google Scholar

- Research which is freely available for redistribution

Submit your manuscript at www.biomedcentral.com/submit
(O) Biomed Central 